\title{
Passing on pediatric donors hearts: Picky or prudent?
}

\author{
Ming-Sing Si, MD
}

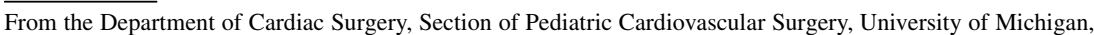
Ann Arbor, Mich.

Disclosures: Author has nothing to disclose with regard to commercial support.

Received for publication Jan 11, 2017; accepted for publication Jan 12, 2017; available ahead of print Feb 17, 2017.

Address for reprints: Ming-Sing Si, MD, Department of Cardiac Surgery, Section of Pediatric Cardiovascular Surgery, University of Michigan, 11-735 C.S. Mott Children's Hospital SPC 4204, 1540 E. Hospital Drive, Ann Arbor, MI 48109-4204 (E-mail: mingsing@umich.edu).

J Thorac Cardiovasc Surg 2017;154:537-8

$0022-5223 / \$ 36.00$

Copyright (c) 2017 by The American Association for Thoracic Surgery

http://dx.doi.org/10.1016/j.jtcvs.2017.01.011
}

Heart transplantation remains the gold standard treatment for end-stage heart disease in pediatric patients. The donor organ shortage restricts the tremendous impact of heart transplantation to the minority of recipients who are fortunate enough to receive one. Therefore, it is quite evident that judicious use of this precious resource is a paramount priority.

Donor allografts are evaluated on both quality and appropriateness for the patient. The desirable pediatric donor heart has normal function, absence or only a short period of cardiac arrest, absence of target antigens for the recipient with preexisting antibodies, appropriate size, and would have a short ischemic time. On the surface, any deviation from these characteristics would make a donor allograft less desirable and would give the implanting team pause.

The ability of cardiac donor allografts with depressed ventricular function at the time of consideration to adequately perform posttransplant has been appreciated for several decades and restudied in more detail relatively recently. ${ }^{1,2}$ Furthermore, the dogma that periods of donor cardiopulmonary resuscitation (ie, downtime) consistently and negatively impact allograft quality has been challenged. $^{3,4}$ In a previous single-center study, Easterwood and colleagues ${ }^{5}$ demonstrated that pediatric cardiac donor allografts previously refused for quality were transplanted successfully and yielded satisfactory outcomes.

In this issue of the Journal, Zafar and colleagues ${ }^{6}$ used the United Network for Organ Sharing database to gain further insight into this issue in a much broader context. They performed a retrospective study of adolescent donor hearts from the time period July 2000 to June 2015 that were refused by pediatric transplant centers and then were accepted subsequently by adult transplant centers. Because adolescent hearts can be used by both pediatric and adult recipients but must be offered to pediatric recipients first, this scenario provided the unique opportunity to study differential acceptance thresholds of pediatric and adult transplant teams.

The key finding of their study is that 855 adolescent donor hearts were evaluated and refused by pediatric heart

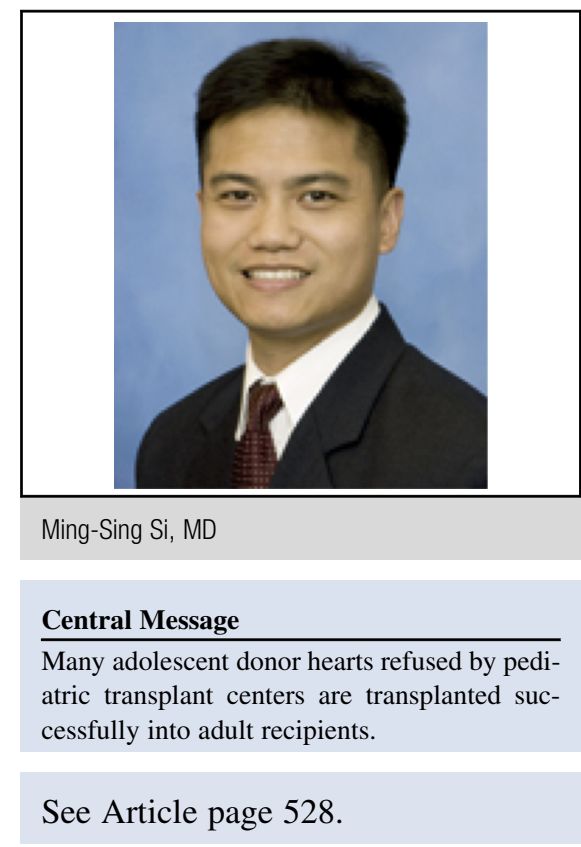

transplant teams for 844 potential pediatric recipients. Fifty-one percent of these adolescent donor hearts ( $\mathrm{n}=517$ ) were refused by pediatric teams primarily because of quality. These 855 adolescent donor hearts were then accepted by adult heart transplant teams. The outcomes of these adult heart transplant recipients were no different from other adult and pediatric heart transplant recipients, suggesting that the quality of these donor hearts was acceptable. Subgroup analysis specifically evaluating the outcomes of the 517 donor hearts primarily rejected for poor quality but that were transplanted into adult recipients also revealed excellent posttransplant outcomes. Furthermore, of the 844 potential pediatric recipients that had refused these adolescent donor hearts, 87 of them died or became too sick for transplant. The authors conclude that refusal criteria for donor hearts by pediatric transplant teams should be carefully evaluated and reconsidered.

This study identifies and highlights a potential area of improvement in donor heart evaluation by pediatric transplant teams. A recent study confirms that donor left ventricular ejection fraction $<50 \%$ was associated with nonuse in pediatric heart transplantation. ${ }^{7}$ This stringent criterion for normal function persists despite previous findings that mildto-moderate donor ventricular dysfunction does not negatively impact pediatric heart transplant outcomes. ${ }^{1,2}$

Although the findings of the study by Zafar and colleagues ${ }^{6}$ were restricted to adolescent donors, it also is 
possible that the same approach to evaluation and high threshold of acceptance of smaller donor hearts by pediatric teams also are similar. Thus, when accounting for all ages, the number of nonused pediatric donor hearts and potential pediatric recipients who could have received a donor allograft may even be greater.

Studies in animals have provided insight into the mechanisms underpinning ventricular dysfunction seen in organ donors. Neurologic injury resulting in brain death results in sympathetic nervous system activation and catecholamine surge. ${ }^{8}$ This catecholamine storm can attain levels that can cause vasoplegia and myocardial dysfunction. Indeed, the recognition of this neurologic injury-induced myocardial dysfunction provided the rationale for hormonal replacement with methylprednisolone, triiodothyronine, and arginine vasopressin, which have become the standard of practice. ${ }^{9}$ Nonetheless, myocardial dysfunction may persist despite hormone replacement, but has been shown recently to be eventually reversible in both children and adults, yielding acceptable donor heart allografts. ${ }^{10,11}$

It is evident that more research into expediting the resolution of myocardial dysfunction in the neurologically injured donor is needed to help achieve the perfect donor heart. Until that obstacle is surmounted, however, further consideration of pediatric donor hearts with imperfect function is needed so that greater use is achieved.

\section{References}

1. Boucek MM, Mathis CM, Kanakriyeh MS, McCormack J, Razzouk A, Gundry SR, et al. Donor shortage: use of the dysfunctional donor heart. J Heart Lung Transpl. 1993;12:S186-90.

2. Rossano JW, Lin KY, Paridon SM, Zhang X, Gaynor JW, Kaufman BD, et al. Pediatric heart transplantation from donors with depressed ventricular function: an analysis of the United Network of Organ Sharing Database. Circ Heart Fail. 2013;6:1223-9.

3. L'Ecuyer T, Sloan K, Tang LW. Impact of donor cardiopulmonary resuscitation on pediatric heart transplant outcome. Pediatr Transplant. 2011;15:742-5.

4. Quader MA, Wolfe LG, Kasirajan V. Heart transplantation outcomes from cardiac arrest-resuscitated donors. J Heart Lung Transpl. 2013;32:1090-5.

5. Easterwood R, Singh RK, McFeely ED, Zuckerman WA, Addonizio LJ, Gilmore L, et al. Pediatric cardiac transplantation using hearts previously refused for quality: a single center experience. Am J Transplant. 2013;13: 1484-90.

6. Zafar F, Rizwan R II, Lorts A, Bryant R III, Tweddell JS, Chin C, et al. Implications and outcomes of cardiac grafts refused by pediatric centers but transplanted by adult centers. J Thorac Cardiovasc Surg. 2017;154:528-36.e1.

7. Khan AM, Green RS, Lytrivi ID, Sahulee R. Donor predictors of allograft utilization for pediatric heart transplantation. Transpl Int. 2016;29:1269-75.

8. Chiari P, Hadour G, Michel P, Piriou V, Rodriguez C, Budat C, et al. Biphasic response after brain death induction: Prominent part of catecholamines release in this phenomenon. J Heart Lung Transpl. 2000;19:675-82.

9. Rosengard BR, Feng S, Alfrey EJ, Zaroff JG, Emond JC, Henry ML, et al. Report of the crystal city meeting to maximize the use of organs recovered from the cadaver donor. Am J Transplant. 2002;2:701-11.

10. Krishnamoorthy V, Borbely X, Rowhani-Rahbar A, Souter MJ, Gibbons E, Vavilala MS. Cardiac dysfunction following brain death in children: prevalence, normalization, and transplantation. Pediatr Crit Care Me. 2015;16: E107-12.

11. Borbely XI, Krishnamoorthy V, Modi S, Rowhani-Rahbar A, Gibbons E, Souter MJ, et al. Temporal changes in left ventricular systolic function and use of echocardiography in adult heart donors. Neurocrit Care. 2015; 23:66-71. 